\title{
La importancia de la memoria histórica de la pandemia
}

\section{The importance of the historical memory of the pandemic}

\author{
Alberto Orozco Gutiérrez* \\ Citar como: Orozco GA. La importancia de la memoria histórica de la pandemia. Acta Med \\ Grupo Angeles. 2021; 19 (s1): s6. https://dx.doi.org/10.35366/101021
}

Los relatos históricos de las pandemias constituyen una evidencia invaluable para el desarrollo de la medicina, desde los reportes de la plaga Ateniense (430 a.C.) descrita por Tucídides, que sobrevivió a ésta y nos permitió enterarnos de los pormenores de dicha epidemia, hasta la influenza $\mathrm{H} 1 \mathrm{~N} 1$; ha habido una gran cantidad de reportes de diversas epidemias que nos han permitido conocer y recordar los sufrimientos de los seres humanos en la lucha diaria con los microorganismos.

Acta Médica del Grupo Ángeles, en colaboración con el Colegio Mexicano de Ciencias Dermatológicas, ha queri- do recopilar una memoria visual y escrita de los procesos dermatológicos de la pandemia de COVID-19, asimismo, el apoyo de reconocidos dermatólogos y el trabajo de la editora invitada, la Dra. María Graciela Guzmán Peredo, han permitido crear una memoria visual que permitirá conocer y recordar la evolución de las lesiones dermatológicas en el COVID-19.

La única forma de lograr un crecimiento y un avance científico sostenido es trabajar duro y en equipo, y es para nosotros un orgullo la colaboración del Colegio Mexicano de Ciencias Dermatológicas en este número especial.

* Editor responsable. Acta Médica Grupo Ángeles.

Correspondencia:

Alberto Orozco Gutiérrez

Correo electrónico:

editoractamedicagrupoangeles@gmail.com

www.medigraphic.com/actamedica

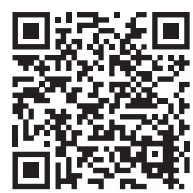

